\title{
Water and the Configuration of Social Worlds: An Anthropological Perspective
}

\author{
Kirsten Hastrup \\ University of Copenhagen, Copenhagen, Denmark \\ Email: Kirsten.hastrup@anthro.ku.dk
}

Received February 1, 2013; revised March 3, 2013; accepted March 17, 2013

Copyright (C) 2013 Kirsten Hastrup. This is an open access article distributed under the Creative Commons Attribution License, which permits unrestricted use, distribution, and reproduction in any medium, provided the original work is properly cited.

\begin{abstract}
From an anthropological perspective, water is not only the sine qua non of life in general, it is also seen to configure societies in particular ways, and to generate particular values. This will be substantiated in four moves. First, the hydrological cycle and other elementals of water will be discussed. Second, we shall zoom in on rivers, transforming natural resources and social communities as they bend and twist. Third, we shall discuss artificially established canals, emulating natural flows, but having their own long-term social and political implications. Fourth, we shall focus on wells, providing nodal points of social life and potential conflict. The article ends with some observations on water as a theory-machine.
\end{abstract}

Keywords: Sociality of Water; Rivers; Contested Flows; Canals; Wellsprings; Virtual Water

\section{Introduction}

In this article, water will be addressed from the perspective of anthropology. From that perspective, water is not only the sine qua non of life in general, it is also seen to configure societies in particular ways and to generate particular values. River flows, canals, and wellsprings frame particular social worlds. My point is that the configurative power of water must be taken into account, if we are to project futures that are not already negatively implicated in the present, or in other words if we are to up-hold a sustainable society.

I shall make my case for the configurative power of water in four moves, each setting a particular framework for a discussion of the meaning and relative social value of water. First, I shall discuss some elementals of water, surfacing in various forms all over the world, and to which all humans relate. Second, I shall zoom in on rivers, which transform natural resources and social communities as they bend and twist. Third, I shall discuss artificially established canals, emulating natural flows, but having their own long-term social and political implications. Fourth, I shall deal with wells, not only in terms of natural wellsprings but also in the shape of reservoirs and deep boreholes tapping groundwater from deep down.

My main ambition is to introduce an anthropological way of thinking about water, which is vital when we approach the question of a sustainable future. This question makes little sense if we disregard humans and societies, and I want to present some images and arguments for taking people seriously as both subjects and objects of water. With respect to the value of water, I shall touch upon numbers and other measures of valuation intermittently, as ways of abstracting water from its social significance, which sometimes contribute to the fading out of the sociality of water.

\section{The Elementals of Water: The Hydrological Cycle and Beyond}

To get started, I want to briefly discuss the hydrological cycle by way of Jamie Linton's book What is Water? [1], pointing to the (ideational) transformation of water from a vital substance to a numerical abstraction by way of modern hydrology. The principal means was the idea of the hydrological cycle, an (old) idea that was first launched in modern science by Pierre Perrault in a work dating from 1674 called On the Origin of Springs. By closely measuring the precipitation, evaporation, and stream flow in a basin at the source of La Seine, Perrault sought to prove that the water of springs derived from rainfalls rather than coming from the oceans via subterranean channels, as popular wisdom went. In the On the Origin of Springs, Perrault delivered what Linton calls the first manifesto of modern water ([1], p. 103, [2]). In his manifesto, Perrault disconnects the essence of a 
spring from its possible usage, relative beauty, and surprising effects; these are of no concern to him. Henceforth, water became an abstract resource that could be measured and counted, and the modern science of hydrology was born.

Of course, hydrology has had a long and uneven history since then, but with Linton it seems safe to say that since 1931 the hydrological cycle has been an established fact. This was (according to Linton) when hydrology made its claim to water as a distinct scientific domain with the publication of Robert Horton's article on "The Field, Scope and Status of the Science of Hydrology” ([1], p. 128ff, [3]). The hydrological cycle became the backbone of the science of hydrology, but it also spilled over into popular imagination. Horton's depiction showed a closed system where the links between the elements could be established mathematically. Since then, the hydrological cycle has become an established fact, and forgotten as a particular representation.

Popular depictions abound, and what they generally share is the fallacy of suggesting that in principle we are dealing with a system in balance; it has become so obvious that it is often seen as "one of nature's grand plans". In the Handbook of Hydrology, it is described in the following way:

The hydrologic circle is the most fundamental principle of hydrology. Water evaporates from the oceans and the land surface, is carried over the earth in atmospheric circulation as water vapour, precipitates again as rain or snow, is intercepted by trees and vegetation, provides a runoff on the land surface, infiltrates into soils, recharges groundwater, discharges into streams, and ultimately, flows out into the oceans from which it will eventually evaporate once again. This immense water engine, fuelled by solar energy, driven by gravity, proceeds endlessly in the presence or absence of human activity ([1], p. 109, [4]).

As pointed out by Linton-and before him by Yi-FuTuan [5] -hydrology is of course deeply marked by a human story ([1], p. 106). First, the model is of course human-made and based on what hydrologists could and thought fit to measure. Second, it masks the fact that the system is far from stable, and that human action, social demands, and political priorities always destabilize the model. This makes it expedient to develop a more nuanced understanding of the place of humans and societies within the hydrological system. People are never simply placed in the environment, they actively interfere with it, and increasingly so.

Water is not an abstraction when seen from the point of view of humans, who experience its many forms and forces: ice, snow, seas, waves, rain, rivers, floods, swamps, wellsprings, ground water, dew, steam — each of which engenders particular meanings and sensations, and makes certain social forms possible or prohibitive. Once established, excess or shortage of any kind of water potentially threatens society; there is thus a balance to maintain, for a particular kind of society to continue. Invoking Marcel Mauss' classical notion of a "total social fact" Orlove and Caton ([6], p. 402) suggest both that water is all encompassing, and takes multiple social forms. While certainly "natural" (albeit in different ways), it is also very much material, political, and bio-political; as such water challenges the very nature/society binary [7].

Although people in the richer parts of the global water catchment rarely have to go without freshwater, for many less privileged it is still a recurrent question of life or death, for children, livestock-and potentially everybody. For all humans, life is a generative, and regenerative force ([8], p. 115). The existential meanings of water also include the sensory experiences of the shifting qualities of water, and their contribution to the deeper meaning of lives and places. This includes not only the feel of water, but also for instance the sounds of water, as so admirably described by Steven Feld [9] in his work on the "waterfalls of song"-creating an acoustically defined social space in Papua New Guinea. In other words, there is a growing literature, testifying to the fact that the social "self" is to a large extent based upon access to water:

...being the only material aspect of the environment that everyone, without exception, has to ingest and incorporate. It forms a major part of the constitution of the self, as well as every other organic object, linking people to the material environment, and to each other... it is therefore, both physically and symbolically, a vital connective fluid, encoded with powerful meanings as a source of life and health, and generative ability ([10], p. 10).

This takes us to another point about water, namely its agentive powers; water does something in society. Water irrigates, inundates, floods, dries up, and creates social tensions as well as transport systems. On an immediate level of perception, it makes life possible, which in some way blurs the boundary between nature and infrastructure ([11], p. 542). Water may obliterate or create value, both economic and moral; this is configured in extensive patterns of sharing and distributing water resources within a community. Water also has deep imaginative implications; it carries people's thoughts towards other shores, farther horizons, deeper meanings, and existential questions. As such it has spurred multitudes of travellers to set out and discover new lands, and once again, new imaginative horizons.

\section{The Bends of the River: Transformations of Value}

Once we move beyond the elementals of water with the 
first inkling of its general configurative power, we may move further towards an understanding of how value is constituted by water. The first case will be that of rivers, creating their own transformative system of values as the river flows and bends. We shall also take a look at canals and dams, forging or arresting the natural flows. But first we shall remind ourselves about the classical philosopher Heraclitus, who from the time around 500 BC reminds us that one cannot step into the same river twice, because it keeps changing. His larger vision was of a world where everything is in flux, from the stars to the grains of sand, and that therefore it is impossible to entertain a notion of universal laws. All depended upon time, place, and the perspective applied. In this section, we shall see how with each new bend of the river, and each new tributary, the social forms are reshaped and values transmuted.

An almost paradigmatic example is Veronica Strang's analysis of the transformations of nature and its resources along the Brisbane River in Australia, where people use the water for a multiplicity of purposes, transforming it to different kinds of value, and where the river is therefore never "the same". "The Brisbane River starts high in the Jimna Ranges in a network of small streams that are often no more than a thread of green in the dusty hills. By the time it reaches the Port of Brisbane, it has been captured, used and turned into many things: beef and vegetables, fruit and wine-things that can be bundled into containers and shipped to the trading partners on which Australia relies”, as Strang's initial portrait runs ([10], p. 9). Her analysis demonstrates how water, as the most basic ingredient in the transformation of "natural" resources into commodities, can become almost anything, but may also give rise to tensions between different groups of people.

Let us follow the flow with Strang and make some observations on the ways in which the river is transformed along the way. In the upper catchment, the river starts in small streams and waterholes that are shared by kangaroos and cattle alike; its "major contribution to human activity is simply to provide water and feed for the cattle who, from the perspective of their owners, convert it into 'beef'” ([10], p. 12). Below the ranges and the region of primary production, reminiscent of colonial times, the river is captured by a couple of dams. They have a dual purpose: one to control the river and protect Brisbane from flooding; the other to store water for domestic and industrial supply. This is where "the river undergoes its first major physical and categorical transformation from being merely 'part of the natural ecosystem' into the vital commercial resource of 'water supply'” ([10], p. 13). The politics of water distribution takes a twist here. Below the dams, still in the words of Strang, the river flows into Queensland's “vegetable and fruit bowl”, an area where it is possible to grow almost everything, and where the farmers physically take water into their hands to irrigate or sprinkle their fields.

Absorbed into the thirsty crops, it becomes all manner of "produce", which is harvested, marketed and, more often than not, packed into the containers awaiting shipment down in Brisbane's port. Thus, taken into the material control of the rural "producers", it becomes whatever crop they choose to farm, applying their knowledge and skill to transform soil, water and seed into the agriculture that defines who they are ([10], pp. 13-14]).

To cut the last part of the story short, it suffices to mention that further downstream water becomes a vital component in industrial production, not to speak of the city's ambitious water distribution schemes, as well as an increasing tourist industry, living off the river's recreational aspects. While the primary producers upstream may not yet feel the increasing pressure upon water, it is fast approaching with a growing urban population further downstream; the shifting values of water along the river already create tension. A sustainable future for the river catchment area cannot accommodate all of the demands for water equally, and the tensions intensify.

To mitigate this, measures and numbers are sought to provide a basis for a just allotment of water resources. But again, numbers are abstractions not realities, and are tailor-made to what is enumerable in the first place; this implies that numbers are themselves generative of particular worldviews. Thus, Helen Verran suggests that the "Australian water market” is constituted by numbers, not represented by them ([12], p. 176). Numbers are materialized relations; three is by definition more than one because of their relation within the series of numerical counting. For relative value to be operational, it must be measured by means of one and only one standard. Verran's story about the systematic side-lining of Australia's many volunteering water-watchers, monitoring the intensity and cleanliness of rivers and streams, and producing ample evidence about their sad state, is owed to this: only one set of proper measurements is accepted. In other words, knowledge by "wrong” measures may be deemed less valid than others if they are not based on the appropriate relations between authorities, instruments, and unified goals.

While the river or the catchment may be one and the same when seen from a hydrological point of view, it bends and twists the human perception of resources and rights, and transforms social and moral values all while it flows according to the laws of gravity and liquidity. Social life along the river is both configured by and configures the flow of water.

\section{The Limits of Canals: Constructed Conflicts of Interest}

Waterflows are often created artificially, whether to sup- 
ply freshwater to cities, discharge wastewater, or irrigate fields. When one looks towards artificial or at least controlled rivers, the challenges of assessing the value of water multiply. Where canals have created new flows of water and transport (while possibly contributed to the closing of others), there is also a new kind of social responsibility towards maintenance. This applies most forcefully when the canals are meant to supply cities with water, or when they are built to relieve cities of wastewater in the interest of hygiene. In the Western world, the last half of the nineteenth century was the time when great engineering projects were conceived that would change the atmosphere of the cities forever. A notable example is the building of the London sewers after "the great stink"-a telling notion-hitting London particularly hard in 1858 in terms of a major cholera epidemic. Having finally worked out that cholera did not spread by air but by contaminated water, a fantastic measure was taken: the construction of underground sewers.

As has been suggested, such efforts and technological feats (also in other countries) became icons of modernity, sometimes also explicitly linked up with nationalist urges [13]. Along with the modernizing quest came a strong sense of clean water and sanitation being a public good, rather than simply a commodity, and this raised the expectations to society ([13], p. 284). This reminds us that the distinction between water and infrastructure is not always easily maintained, because the channelling itself fosters a particular relation between society and its citizens ([11], p. 556).

This is still an important issue when it comes to other modern water infrastructures, operating on a transnational rather than a national scale. I am thinking of such a major construct as the Suez Canal, officially inaugurated in 1869, and always a troubled passage due to world politics. There is also the Panama Canal, constructed in early $20^{\text {th }}$ century, likewise to facilitate Western trade routes. These gigantic waterways take us directly to the issue of the value of water, as deeply embedded in social systems and life forms. There is of course the obvious (?) value connected with the quicker transport between the continents, but there is certainly more to it. There is also very much a strategic value-as we now know from the Somali pirates placing themselves at the entry to the Red Sea, and from countless Middle Eastern conflicts over the control of the Suez Canal.

The Panama Canal provides a vivid example of a conflict of interest linked to the different kinds of water, and the relative value of nature's gifts and modes of living. As Ashley Carse has recently discussed, for the Panama Canal to function, and thus to connect the two big oceans and facilitate global trade, an enormous amount of freshwater is required [11]. For each of the 35 - 45 ships that transit the canal daily, 52 million gallons, or c. 200 mil- lion litres of fresh water is released into the Atlantic and Pacific Oceans through the impressive system of locks and leverages. This water comes from the surrounding watershed, and ultimately from rain, and to keep the Canal going, it is necessary to manage the watershed rather diligently, and it has even been necessary to create an artificial lake. At several points in time, for instance in the 1970s, water became scarce, and governmental measures were needed lest the canal dry up. The anatomy of a crisis (in 1977) was vividly described by a certain Dr. Wadsworth, at an US Strategy Conference (the canal was still under US-authority; it was handed over to Panama shortly after):

In May of 1977, the passage of an above average number of ships, an increased use of water for hydroelectric power and the domestic supplies of growing cities, and the production of timber, food, and forage crops within the Canal watershed led to a dramatic demonstration of the limits of the capability of the water system. The surface of Gatun Lake dropped to 3.1 feet below the level required for full Canal use. Some ships sent part of their cargo across the isthmus by land, reloading at the other coast, and certain bulk cargo shippers even abandoned the Canal, sending very large carriers around the Horn. In 1977, this predicament coincided with a serious drought, and this was seen as a harbinger of what could soon take place every year... Deforestation and cultivation in areas adjacent to the headwaters accentuate both flood losses through the spillway and low flow in the dry season. (Wadsworth 1978; quoted in [11], p. 549)

The conclusion was that only a massive effort of (re-) forestation could restore and stabilize the capacity of the Canal. This created a major local issue, since the "problem" became identified with the small-scale cultivators in the surrounding lands, now cast as invaders of the forests troubling the proper management of the Canal. While just a little earlier, the campesinos that farmed those landscapes had been seen as part of the solution to Panama's development, they now became the problem. Generally, we can see how the Panama Canal configures both global relations and local land-use possibilities.

The main message from this last example (as from the previous ones) is that water-flows-whether rivers or canals-create their own value systems within landscapes that are always both natural and social, both resource and infrastructure.

\section{The Spring of Wells: The Reality of Virtual Water}

The last case will be that of wells, centring communities on particular, localized sources of water, and sometimes creating major tensions between them. The value of water seems more obviously equal to everyone, but equality is not necessarily the net result. In connection with the 
Panama Canal, we noted how an artificial lake had to be made to form a reservoir of water for the management of the transport system, requiring staggering amounts of fresh-water to function. Looking back briefly at the hydrological cycle, we note that lakes in general play an important part both in the surface flows and in the general water cycle. This also applies to groundwater, which is a hidden water resource with immense importance to life in regions that are otherwise arid or semi-arid. When I speak of wells, I think of located wellsprings, big or small, nature made or artificially created-that centre social life in a very different way from waterflows, which string out social life.

I shall start with some nomads in West Africa, living on the brink of the desert in South-eastern Mauretania; the Kounta nomads have camels and goats and traditionally they would move rather freely over a vast region. Said a man to the ethnographer: "There are no boundaries here-we can move wherever we want, let the animals graze where we want, and get water from all the wells we want. Here, in the badyya, we share the resources. Everything depends on solidarity (assabiyya)" ([14], p. 185).

This statement never actually implied that there were no rules regarding access to water, only that the resources mentioned already belonged to all members of the agglomerated Kounta factions. Other tribes were not permitted to extract water from the wells without prior agreement with the head of the Kounta. Under ordinary circumstances, the implicit territoriality of water would actually provide a functional framework for most of the nomads, who would carefully read the environment and know when to move to new, appropriate places for water and grazing. However, droughts are now threatening the fragile balance of the nomadic groups. Many nomads have moved to the city of Nouakchott, where there are not many livelihood strategies for the rural immigrants. Others remain in the desert, in ever more circumscribed conditions. This is where the natural and the social dimensions conflate. "In order to adapt, the Kounta activate not only their internal network of memories and knowledge of the environment, but also their social networks” ([14], p. 193). When water becomes scarce, as it does currently, the nomads are bound to congregate around a limited number of wells and undertake complicated negotiations about relative rights of access. They must agree to a system of controlled access, so as to satisfy the needs of all local actors. Next year, the water resources may be elsewhere. "In case of prolonged droughts, it is not unusual that a more distant network is activated, permitting members of nomadic pastoral families to take up residence in areas outside the Kounta heartland for longer periods of time" ([14], p. 194).

We can see how in this case, resilience is as much a so- cial as an environmental issue [15]. People, who depend on wells, equally depend on each other, when the wells dry out, and water becomes even scarcer that usual. This is what is happening in the Kounta's region these years, where the narrowing down of opportunities is further aggravated by the political situation in the borderland region of Mauretania and Mali, fraught with political conflict. Another troubled story within the same general region is the well-known war in Darfur, which has been deemed one of the most serious humanitarian catastrophes ever. While it has often been portrayed as a tribal conflict, one of the root causes is to be found in the drought that sent hundreds of thousands of small-scale agriculturalists on the move, thus transgressing the boundaries of others. Again we have here a pattern of traditional oasis life, mentally figured as tranquil, but over and again punctuated by deep social and political tension related to the scarcity of water-at least also related to water. In Sudan, the result was not a movement into the capital, which few could afford, but a move into camps for the internally displaced [16]. The value of water here became one of sheer survival.

The very fact that wells-and with them the oasesare so narrowly located and not always plentiful or reliable, places people in a potentially strenuous relationship to each other. While, environmentally, the well exerts a centripetal force, socially, this may transform into a centrifugal pattern of exclusion. In the desert, nomad groups may disband or move to the city, where they rely on water vendors, charging according to season. In cities, where water supply cannot always be taken for granted, "artificial" wells may be set up in the shape of water tanks. In megacities, often resulting from mass-migration from the hinterlands, this is no small challenge. A recent study of water management in the city of Mumbai (India) shows how the urban poor have nevertheless succeeded: "In cities that are always and already divided, the urban poor have struggled to establish themselves as a constituency entitled to public services. The fact that they continue to draw water and live in cities like Mumbai suggests that they have had some measure of success" ([17], p. 219). The settlers are in many ways excluded from modern amenities, but large tanks are being filled by the water authorities-emulating wells-from where people can fill their own containers.

Let us now make a last move, this time to Egypt, before closing this section on the social life made possible (or impossible) by wells. It is well known that Egypt is in important ways shaped by the Nile. The great Aswan Dam in the south has regulated the flow of the Nile since the $19^{\text {th }}$ century, being yet another token of modernization. With a growing population and greater urban concentration, the "naturally" irrigated valley no longer satisfies the need for agricultural produce. Great land-recla- 
mation projects have been launched, either by tapping into the Nile, and sending water through pipes into adjacent valleys, sometimes creating artificial lakes [18]. Here local farmers are able to tap into the water, and they do so by means of their privately owned pumps and pipes, for which they are in principle licensed, but not always in practice. These outlets figure as more or less individualised wells. While the ambitious targets for land reclamation are not quite met, a "very vibrant process of desert transformation is underway” ([18], p. 519). As Jessica Barnes has it:

Water is central to this process of landscape transformation. It is not the only thing needed to reclaim the desert; farmers must also level the surface, remove rocks, and develop the fertility and texture of the soil. But whereas fertilizers and other soil treatments can be easily purchased, water cannot. Water is therefore the limiting factor of agricultural expansion. Since the desert margins lie above the cultivated land of the valley and delta and the existing network of water distribution canals, farmers have to use pumps to lift the water. Pumps are therefore the limiting technology for agricultural expansion ([18], p. 518).

Taking this a step further, we may agree with Barnes when she says, that "the pump is not just a technology for delivering water, but a technology for building community" ([18], p. 518). The inverse of that equation is of course that it also creates fissures in society at multiple levels. Barnes describes the illicit draining pipes and the recurrent competitions between farmers over water, often favouring the city-farmers who are really just making an investment and are able to draw out huge profits. Meanwhile the small-scale landholders have fewer means to invest in pumps and need to take matters in their own hands-by making holes in existing pipes and illegally taking out water for their own fields, creating illicit wellsprings.

Technology only takes the community so far, however. Water is dwindling even in the more promising areas, and cotton fields have given way to less water demanding onions and olives. In some regions, the increasing water scarcity from the artificial lakes and streams has been repaired by the making of deep boreholes tapping into the groundwater, notably in the West Delta region, also studied by Barnes. Being an informal land reclamation project, it is financed by wealthy farmers or investors, who-by means of expensive pumps reaching down to $200 \mathrm{~m}$ below the surface-have been able to transform the desert into lush orchards. Again, this wonderful techno-nature comes at a price. The water table is dropping about one metre per year, and the salinity of the groundwater has increased, and even people who until now were not concerned about the issue of the water's provenance and the pumps' effect on the underground flows, have started to worry, and ask international agencies for help ([18], p. 530).

The Egyptian cases highlight the fact that water for irrigation and for land reclamation is mediated by technology, and illustrate how the combined techno-nature in turn affects societies and may reshape them in both time and space. The cases also draw our attention to the notion of "virtual water" by which I shall end this section of wells and other reservoirs. The Egyptian orchards, as well as the (disappearing) cotton fields and olive groves point beyond the local needs to external and even overseas markets. The water, however, is local. When pumped out and drained up by fruit and vegetables, to be sold and consumed elsewhere, the local water from the deep wells is transformed into virtual water, a measure of the amount of water that went into the production at its site, and transported elsewhere for consumption. Virtual water is defined as "the volume of freshwater used to produce the product, measured at the place where the product is actually produced. It refers to the sum of the water use in the various steps of the production chain" [19]. It is well known that the production of one kg beef requires immensely more water than the production on one $\mathrm{kg}$ of apples. Eating beef thus means consuming an immense amount of virtual water.

The salient point about virtual water is that it has become spatially disconnected from the actual consumers, and has become part of a global market of tradable goods - tending to hide water consumption from view, so to speak ([20], p. 50). If we add global transport to this, it is abundantly clear that given the present freshwater shortage, we need to develop more sustainable water use, and to alert consumers to the hidden use of water in daily life, and to the water footprint left from, say, the import of goods from elsewhere ([20], p. 44). While technologies of pumping and transport, as we have seen, may make trade in virtual water possible, they come with a cost to sustainability. In this case, numbers and measures of water footprints may serve a very precise purpose of raising the awareness about both unsustainable water consumption and emergent global inequities related to the commercial values of particular kinds of produce, draining local water resources for people at the actual well.

Closing the discussion of wells, centring social life on particular water-resources, we can now see how they may actually also be nodal points in larger flows of virtual water.

\section{Fluid Environments: Water as Theory Machine}

The general message is that water is a powerful resource, not only for survival and production, but also and as significantly for the configuring of particular social forms 
and social values. Water connects and disconnects; it equates and disequates. All while being an essential of social life, and it resists definitive control and containment. It remains a liquid resource.

Stefan Helmreich has suggested that water has become a theory-machine [21]. He argues "that seawater has moved from an implicit to an explicit figure for anthropological and social theorizing, especially in the age of globalization, which is so often described in terms of currents, flows, and circulations” ([21], p. 133). Indeed, he suggests that globalization may be seen in terms of "oceanization", much in the manner of Zygmunt Baumann speaking of the present times as "liquid" [22]. The larger point is that water itself offers new ways of thinking and theorizing about the world, which has so far been thought of mainly in terms of lands, nations, and sedentary social forms. In seeing water as a "theory-machine" we may take the discussion of the configuration of social forms to a new level of generalization, substituting the still-life image of society as an entity, with a dynamic image of societies in constant movement, as they reformat themselves in response to fluid environments.

The hydrological cycle is but one theory among others made with water. The main challenge is to introduce people and societies into the model of the not-so-stable circulating water system, which is most often abstracted from the experiences and reflections of water-sentient citizens. The question is to what extent we live in water-cultures [23]; the answer rests with careful analyses of the social life of and with water. At a more general level it seems pertinent to initially acknowledge the actual liquidity and social malleability of water, which goes a long way to intimate its configurative power in social worlds.

\section{Acknowledgements}

I wish to thank the ESF for organizing the Summit on Water: Unite and Divide, giving us all an opportunity to reflect on a vital issue, and for inviting me to contribute. I also want to gratefully acknowledge the European Research Council for the Advanced Grant that has enabled me to run a comprehensive project on Waterworlds.

\section{REFERENCES}

[1] J. Linton, "What is Water? The History of a Modern Abstraction," University of British Columbia Press, Vancouver, Toronto, 2010.

[2] P. Perrault, “On the Origin of Springs," Hafner, New York, 1967.

[3] R. Horton, "The Field, Scope and Status of the Science of Hydrology," Transactions of the American Geophysical Union, Vol. 12, No. 1, 1931, pp. 189-202. doi:10.1029/TR012i001p00189-2
[4] D. R. Maidment, Ed., "Handbook of Hydrology,” McGrawHill, New York, 1993.

[5] Y.-F. Tuan, "The Hydrologic Cycle and the Wisdom of God: A Theme on Geoteleology," University of Toronto Press, Toronto, 1968.

[6] B. Orlove and S. C. Caton, "Water Sustainability: Anthropological Approaches and Prospects,” Annual Review of Anthropology, Vol. 39, 2010, pp. 401-415. doi:10.1146/annurev.anthro.012809.105045

[7] K. Bakker, "Water: Political, Biopolitical, Material," Social Studies of Science, Vol. 42, No. 4, 2012, pp. 616-623. doi:10.1177/0306312712441396

[8] V. Strang, “Common Senses: Water, Sensory Experiences and the Generation of Meaning," Journal of Material Culture, Vol. 10, No. 1, 2005, pp. 92-120. doi:10.1177/1359183505050096

[9] S. Feld, "Waterfalls of Song. An Acoustemology of Place Resounding in Bosavi, Papua New Guinea,” In: S. Feld, S. and K. H. Basso, Eds., Senses of Place, School of American Research, Santa Fé, 1996, pp. 91-135.

[10] V. Strang, "Turning Water into Wine, Beef and Vegetables: Material Transformations along the Brisbane River," Transforming Cultures Journal, Vol. 1, No. 2, 2006, pp. 9-19.

[11] A. Carse, "Nature as Infrastructure: Making and Managing the Panama Canal Watershed," Social Studies of Science, Vol. 42, No. 4, 2012, pp. 539-563. doi: $10.1177 / 0306312712440166$

[12] H. Verran, "Number as an Inventive Frontier in Knowing and Working Australia's Water Resources," Anthropological Theory, Vol. 10, No. 1-2, 2010, pp. 171-178. doi:10.1177/1463499610365383

[13] M. Kaika, "Dams as Symbols of Modernization: The Urbanization of Nature between Geographical Imagination and Materiality," Annals of the Association of American Geographers, Vol. 96, No. 2, 2006, pp. 276-301.

[14] C. Vium, "Nomad_Scapes. Mobility and Wayfinding as Resilience among Nomadic Pastoralists in the Islamic Republic of Mauretania,” In: K. Hastrup, Ed., The Question of Resilience. Social Responses to Climate Change, The Royal Danish Academy of Sciences and Letters, Copenhagen, 2009, pp. 178-196.

[15] K. Hastrup, "Waterworlds. Framing the Question of Social Resilience,” In: K. Hastrup, Ed., The Question of Resilience. Social Responses to Climate Change, The Royal Danish Academy of Sciences and Letters, Copenhagen, 2009, pp. 11-30.

[16] A. Hastrup, "The war in Darfur. Reclaiming Sudanese History,” Routledge, London, 2012.

[17] N. Anand, "Making Connections: Accessing Water in Mumbai's Settlements,” In: H. P. Hahn, K. Cless and J. Soentgen, Eds., People at the Well. Kinds, Usages, and Meanings of Water in a Global Perspective, Campus Verlag, Frankfurt/New York, 2012, pp. 215-231.

[18] J. Barnes, "Pumping Possibility: Agricultural Expansion through Desert Reclamation in Egypt," Social Studies of Science, Vol. 42, No. 4, 2012, pp. 517-538. doi: $10.1177 / 0306312712438772$ 
[19] A. Y. Hoekstra and A. K. Chapagain, "Globalization of Water: Sharing the Planet's Freshwater Resources,” WileyBlackwell, Oxford, 2008.

[20] S. Meissner, "Virtual Water and Water Footprints: Global Supply and Production Chains and Their Impacts on Freshwater Resources,” In: H. P. Hahn, K. Cless and J. Soentgen, Eds., People at the Well. Kinds, Usages, and Meanings of Water in a Global Perspective, Campus Verlag, Frankfurt/New York, 2012, pp. 44-78.
[21] S. Helmreich, "Nature/Culture/Seawater," American Anthropologist, Vol. 113, No. 1, 2011, pp. 132-144. doi:10.1111/j.1548-1433.2010.01311.x

[22] Z. Bauman, "Liquid Times. Living in an Age of Uncertainty,” Polity Press, Cambridge, 2007.

[23] W. Bijker, "Do We Live in Water Cultures? A Methodological Commentary,” Social Studies of Science, Vol. 42, No. 4, 2012, pp. 624-627. doi:10.1177/0306312712441690 